\title{
Education in Tourism Industry-Challenges and Opportunities
}

\author{
Pendidikan dalam Tantangan dan Peluang Industri Pariwisata
}

\author{
U. Yu. Abduvakhabova \\ International University of Tourism, Uzbekistan \\ Email to Correspondence: umida4080@gmail.com
}

\begin{abstract}
The aim of the article is to define, analyze and suggest ways of solution of the influence of learning foreign languages problems to develop international tourism in Uzbekistan. It is emphasized that the knowledge of foreign languages is important for the further development of international tourism, because the tourism industry is closely connected with foreign languages. Comparative analyses of different methodologists and scientists' points of views was carried out in literature review to match different approaches of most effective way in teaching foreign language for specialist in tourism industry. For the analysis, pedagogical technologies that are often used in the teaching process and technologies that are little known in pedagogical work, which could be very effective, were selected. The selection was carried out through analysis of literature in the field of pedagogy: studying the experience of innovators (Shchukin A.,Sparks R.L., Ganschow L. and others), as well as the experience of teachers of modern school. It is concluded that international tourism can contribute to increasing the motivation and efficiency of learning a foreign language.
\end{abstract}

Keywords- Tourism; International Tourism; Foreign Languages; Business Tourism; Linguistic-Educational Tours; Independent Tours

How to cite: Abduvakhabova U. Yu. (2020) Education in Tourism Industry-Challenges and Opportunities. IJLER 6 (0). doi:

10.21070/ijler.2020. V6.472

\section{INTRODUCTION}

In the Republic of Uzbekistan, consistent reforms are underway to develop the tourism sector as one of the strategic sectors of the national economy, which in the long term will help to solve such important social and economic tasks as job creation, diversification of the economy and accelerated development of regions, increasing incomes and quality of life of the country's population. Due to the dynamic economic growth of the country, its rich historical heritage, tourist professions remain one of the most popular today. Modern living conditions contribute to the active development of the tourism industry and service sector.

The growing demand for quality tourism and hotel services, as well as services in the service sector determines the need for qualified professionals in these areas. Graduates should have theoretical knowledge, practical skills in their chosen fields of study, readiness to solve professional problems in their respective professional activities, as well as general cultural and professional competences in the areas under study.

When applying for a job in a travel company or a prestigious restaurant, hotel, etc. one of the first questions of the employer will be the question of how many and what foreign languages the applicant speaks for the job. In almost any sphere of life of the society, especially in the work of a tourism manager and hospitality manager, knowledge of a foreign language is of great importance for specialists, because it is a means of communication with representatives of other cultures, including in the field of international tourism and hospitality. Candidates for work in tourism are set high requirements: he must have good experience, be inquisitive, active, and are specified and additional skills, including knowledge of a foreign language. Knowledge of a foreign language helps to compete successfully with other candidates for a vacant position, as employees in the field of tourism should be able to offer their services in a foreign language, primarily in English. This impresses foreign clients and has a positive impact on the reputation of a tourism company and on the productivity of its work. Accordingly, we can assume that the requirements to the candidate for employment are not overstated, but a necessary condition for the productive work of the tourist company [1] . Thus, according to the requirements of profession, graduates in the fields of tourism and service training should have the ability to communicate orally and in writing in foreign languages, be prepared to work in a foreign language environment and carry out intercultural communication in FL as part of their professional activities. Attention should also be paid to the promotion of respect and tolerance for the cultures and customs of other countries and peoples, and tolerance of national, racial and religious differences.

Students in the fields of "Tourism and Service" should 
be able to master the FL to the extent necessary to obtain information from foreign sources; be able to use their knowledge of FL in their professional activities; be able to master the basics of business communications and speech etiquette. The main goal is the development of professional competence implies the ability of the student to organize his or her foreign-language activities adequately to the situations of professional communication. Obviously, a professionally-oriented approach should be a priority in the training of the students. In modern conditions the teaching and learning foreign languages is focused on an interactive basis, which implies the organization of intensive dialogue between the teacher and preferably students in groups. It happens by means of modeling the situations of real professional communication, creating conditions that are as close as possible to the activities of a specialist in the field of tourism and service.

According to the results of monitoring the employment of graduates with knowledge of foreign languages $80 \%$ of respondents confirmed the fact of their employment in the direction of training specified in the diploma of higher professional education, i.e. in tourism and hospitality. To develop highly professional education in tourism sphere International Tourism University "Silk Road" was founded in Samarkand on June 28, 2018 on the initiative of the President of the Republic of Uzbekistan Shavkat Mirziyoyev, nominated at the SCO Summit in Qingdao (China). Today, the University is one of the most famous and prestigious higher education institutions and the first university in the field of tourism in the Republic of Uzbekistan where all subjects are taught in English by teachers from leading foreign higher education institutions. The aim of the University is training a competitive specialist in the modern world, a person with knowledge of at least one foreign language. Students strive to improve their knowledge of several foreign languages, simultaneously with acquiring a profession in tourism. So what exactly is done to provide tourism industry with highly educated specialists?

For the formation of the system of foreign language teaching, there was a need to define the profile of foreign language teaching in university with tourist orientation. The choice of a profile of training is caused by the concept of the educational organization, availability of trained personnel, relevance of this or that profile, social order of the society. According to the scientist-methodologist A.N. Shchukin, the profile of foreign language teaching is a complex type of training in a certain field of knowledge, which depends on the possibility and peculiarities of the educational institution, as well as on the wishes and needs of students studying a foreign language [2] . In modern methods of teaching foreign languages, preschool, school, philological, non-philological, course and distance profiles of foreign language teaching have developed and been justified [2] . To determine the profile of foreign language teaching in a tourism higher education institution, we can compare two of the above, namely, philological and non-philological. According to the concept of the scientist-pedagogue I.L. Bim, the philological profile of teaching allows to provide free knowledge of the language within the borders close to the level of a native speaker and the possibility of professional activity as a teacher, translator, specialist philologist [1] . It can also serve as a basis, foundation for further specialization, e.g. focusing on more diverse and possibly more demanding specializations.

In the non-philological profile, a foreign language can serve not only as a goal, but also as a means of learning another non-linguistic subject area, such as touring, computer science, public relations, restaurants, hotels, etc., providing language skills in professional and business communication with a predominant ability to communicate in writing (reading, writing). A characteristic feature of foreign language teaching in a tourism university is the practical orientation of classes. According to the curriculum of IUT, the number of hours dedicated to the study of the main foreign language - English, is 60 hours of practical classes per year (1st-3rd courses), the same attention is given to the second foreign language-optional (French, German, Chinese, Russian), from 2nd to 4th year - 60 hours. The educational disciplines "Academic writing" and "Business English" are allocated 96 hours of practical lessons per year (3-4th year). Insufficient number of hours allocated for practical classes increases the role of students' independent work in a foreign language, makes the use of intensive methods and means of education, including multimedia relevant.

Dudley-Evans and St John [2] considered English for Specific Purposes (ESP) a multi-disciplinary activity in that the specificity in the ESP teaching practice is to be based on the insights of researchers of the disciplines or professions ESP serves. That's why they proposed a multidisciplinary approach to ESP that has two main aspects:

1) ESP teachers must be willing to deal with other disciplines and,

2) the teachers need to draw on the insights of researchers in other disciplines.

Some studies help to understand the use and function of spoken and written texts in the particular disciplines and professions. In case of English for Business texts on the human resources management and management training, indicate what are common thought patterns, communication and cognitive styles of people in business.

At the same time cultural differences have to be accounted for, thus elements of cross-cultural communication training can be applied also in ESP teaching. According to Dudley-Evans and St John [2] , ESP has had its impact on other disciplines. Thus, the content of teaching at non-linguistic higher schools takes into consideration interdisciplinary links with students' profile of study as indicators shown in the Table 1.

However, the main approaches on the basis of which 
Table 1. Types of interdisciplinary links atnon-linguistic institutes

\begin{tabular}{ll}
\hline Types of interdisciplinary links & Realization of interdisciplinary links \\
1. content-information & - professionally-oriented topics in correspondence with the \\
& profile of education; \\
& - specialized texts and situations; \\
& - specialized vocabulary. \\
& - incorporation of language and communicative knowledge \\
& and skills for conducting professional activity; \\
& - incorporation of language and communicative knowledge \\
2. operation-action & and skills for searching professional value material or infor- \\
& mation. \\
& - construction of system of methods, techniques, forms \\
& for teaching FL and communication within professionally- \\
& oriented topics and interaction moods; \\
& - enlarging professional knowledge via target language \\
\hline
\end{tabular}

the ESP teaching is organized are the followings:

Content-based Learning is an instruction in which teaching is arranged around the content of information that students will acquire. It joins language learning to content/subject matter and engages them both concurrently.

Task-based Learning: This type of learning proposes tasks as useful vehicles and instruction in LT. This could be a problem solving activity or a project, but the task should have a clear objective, appropriate content, a working/application procedure, and a set range of outcomes. As learners work to complete a task, they have abundant opportunity to interact. During interaction they facilitate language acquisition, they get to listen to the language which may be beyond their present ability, but which may be assimilated into their knowledge of the target language for use at a later time.

Content and language integrated learning presupposes to enhance learners' linguistic competence thanks to a higher amount of a target language exposure. Among most favorably influenced by this kind of learning is learners' lexicon. Through receiving FL input in different content subjects learners acquire more profound knowledge and specialized terminology for their future profession. But we should take into consideration that at vocational colleges we teach 1) general English and 2) specialized English. At the same time content-based instruction is aimed to use of socially oriented themes, represents an effort to link students with the world in which students live.

Based on the above, mastering oral communication skills in a non-philological profile is quite difficult, so the focus should be done on written communication (reading and writing). It includes several types of professional speech activities:

- in reading and translation: reading of printed, handwritten and electronic texts in order to extract the necessary information and its analysis, in particular, reading texts in the specialty (training courses for authors E.V. Moshnyaga "Hospitality Tourism", "English for Travel", G. Sayrett "English for Travel Agencies" (English);

- reading and translation of original texts in the specialty with partial reliance on the dictionary (advertising booklets, leaflets, descriptions, tourist testimonials), documents of legal nature (contract for tourist services);

- written and oral translation from and into foreign language of information related to the sphere of the main professional activity (using the dictionary); development of the skill to overcome various types of language difficulties (lexico-phaseological, grammatical, stylistic, etc.);

- on writing: the ability to prepare business documentation (letters, contracts, contracts, faxes, e-mails), business correspondence, $\mathrm{CV}$ (curriculum vitae - description of life and professional skills).

In created situations of professional character, it is necessary to pay attention to modeling of the social and subject content of future professional activity that will help students to realize its essence, requirements to the professional, to construct mentally the image of the expert capable to carry out tasks effectively, to correlate it with the image of own "I" and to develop strategy of actions directed on achievement of desirable result. The main types of work include playing out communication situations, discussing professionally important issues, discussions, as well as role-playing, dramatization, and interviews. The use of the project method and presentations contributes to the mastery of professional communication.

The use of interactive learning technology develops the ability of students to independently transfer previously acquired knowledge into a new situation, to find solutions to the problem, to apply previously learned methods of activity to solve it, to learn to establish dialogue relations with partners in the framework of professional communication. The interaction of students, limited to memorizing and reproducing the dialogues and situations presented in the textbooks, is not pedagogically effective. 
Especially if the focus is on the emotional and semantic neutrality of statements, if students are physically and socially fixed in the classroom, if other means of communication, including eye contact, implicit meanings, intonation, pauses, tempo, timbre of voice and non-verbal components of speech, are not implemented in the course of interaction.

Case studies have also been widely used as a teaching method and as part of professional development, especially in business and education. Method case-study is widely used in the Education System as a modern professional oriented teaching technology.

Case-study is taken from the English words "case" that means: state, situation, event and "study" means learning and analyzing.

\section{Methods AND MATERIAls}

Method case-study can also be called the method of concrete situations based on the problem analyses directed to solve concrete tasks, i.e. cases. Method of case study belongs to active method of teaching. The aim of case study is to analyze case problem and solve it in cooperative activity of the learners. It supposes to study case problem and work out its practical solutions. At the end of the collective work the best solution is selected. This method can be used with success in all spheres of education while in entrepreneur industry which is tourism considered to be, case study is especially effective.

There are two classic schools of case study:1) European (Harvard University); 2) European (Manchester University).

The first (American) supposes to find out the only correct solution of the problem. The second (European) supposes several variations of the solution.

At present Case study method occupies a leading position in education and activity used in abroad. It is one of the most effective means of teaching and forming the skills of solving problems. Situation based teaching according to the methodology is intensive training of the students using video materials, computer and program providing. Within the period of study at the University a student can work with hundreds of cases. The problem of implementing case-study method into education system is one of the very actual problems of the present day. There are two tendencies:

1. It is oriental not only to receive concrete knowledge, but also to form professional competence, skills and subskills of mental activity, to improve personal abilities among which a special attention should be focused on abilities of teaching and also forming the skills of reinforce the process on the mass of information.

2. It is aimed to improve the quality of specialists, the ability of optimal behavior in different situation.

The use of case study in education motivates to learn FL and creative thinking in solving problems. The char- acteristic features of case-study is to form problem situations on the bases of factors taken from the real life. For effective of using case technology in the process of teaching it is important two factors:

- a good case problem

- a definite methodology of using it in the teaching process.

This method is used in concrete situations for solving case problems special worked out on the basis of tactic material with the aim of analyzing and using them in the process of teaching. While working on the problem learners work in cooperation and they learn analyzing and taking solution.

Case-study is quite simple method. It is aimed to acquire knowledge on the target language and solve problems. The learners' task here is to five different solution of the problem and select best of them. Case-study is oriented not getting ready information but to work out the solution of the problem in cooperation. The casestudy method is an instrument of implementing theoretical knowledge into practice. It also helps the learners to be independent, to develop critical thinking and express their ideas argumentatively.

The principle difference of the case-study method from traditional methods is that learners act freely, without psychological barrier and expressing their ideas and acquiring knowledge. This democratic behavior of the learners and the process of teaching is emphasized. For achieving good results in using the case-study method it is important both interpersonal and interpersonal activities of the learners.

A case (module) of concrete situation is worked out. It should be taken from real life and answer needs of the learners for getting information. Teacher's role here generating questions, fixing answers and bear for discussion, i.e. he is the manager of the creative process. The priority of this method is that by analyzing the situations learners improve their knowledge, form practical skills of solving problems, and also improve professional skills characteristic for a foreign language teacher.

While working in groups learners improve their collective work skill.

A good case problem should meet for the following requirements:

- correspond to the aim and the degree of difficulties of the case;

- illustrate some aspects of professional activity;

- actual at present day;

- illustrate typical life situations;

Following R.Sparks, we believe that in this form of speech activity it is necessary to focus on objective diagnostic tools, choosing, in particular, written testing (input, intermediate, final) [2] ; - in listening the main emphasis is made on the formation of the ability to select the basic information during listening to the text of average duration (2-3 minutes) with the "removal" of a cer- 
tain part of the difficulties with the help of a number of preparatory exercises and familiarization with the form of subsequent control (scheme, tables). The teacher focuses on building monological and dialogical statements with predetermined content (description, narration, discussion) and invites students to take part in discussions on specialized topics (travel, hotel accommodation, national cuisine, etc.).

At present, foreign language teachers have gained considerable independence in choosing the means, methods and forms of teaching, as well as in creative thinking about the content and ways of implementing program requirements. But despite this, it should be noted that the leading position is occupied by methods and technologies based on a personality-oriented approach, among which should remain:

- an atmosphere in which the learner feels comfortable and free; an incentive for the learner's interest, a desire to practically use a foreign language, as well as the need to learn;

- the personality of the learner as a whole, as well as his involvement in the learning process, taking into account his feelings, emotions and sensations, which should relate to his real needs, stimulate his speech, cognitive, creative abilities;

- create situations in which the teacher is not the central figure; the learner should be aware that learning a foreign language is more related to his personality and interests than to the teacher's methods and teaching aids;

- provide for different forms of classroom work: individual, group, collective, fully stimulating learners' activity, autonomy and creativity.

All of the above criteria can be implemented in the use of interactive forms and methods of teaching, which show the new possibilities associated with the establishment of interpersonal interaction through external dialogue in the process of learning the material. Foreign language today is not just one of the university disciplines, but a necessary component of professional training and is aimed at the formation of professionally significant qualities and comprehensive development of the student's personality. Lessons on the basis of professionally-oriented approach, complex application of active methods and interactive teaching technologies, selection of teaching content having professional significance will contribute to the formation of competent specialists in the field of tourism and service.

As we can conclude knowledge of foreign languages is important for further development of international tourism. The tourism industry is closely connected with foreign languages as travelers feel they need to know at least one foreign language (English is considered the main language of international tourism, because it was the language that had a serious impact on the development of international relations). English is an international language not only in tourism, but also in business, education and trade, science and technology. Regardless of the language spoken in a particular country, the role of English remains significant, and along with its importance, culture is transmitted.

Summarizing the abovementioned, it should be noted that the non-philological profile of education determines optimal conditions for the functioning of the foreign language teaching system in a tourist higher education institution, including goals, objectives, content, methods, principles and means of education. It promotes practical language acquisition only in the areas of professional communication, while the philological profile assumes fluent knowledge of the language at the final stage of specialist training.

\section{REFERENCES}

[1] P. Ur, "Course in Language Teachin," and others, Ed. Cambridge: Cambridge University Press, 1996.

[2] I. L. Ploughman, "Formation of intercultural communicative competence of students in the process of professional training," and others, Ed. Russian: Institute of Sociology of the Russian Academy of Sciences, 2017, p. 638.

\section{Conflict of Interest Statement:}

The author declares that the research was conducted in the absence of any commercial or financial relationships that could be construed as a potential conflict of interest.

\section{Article History:}

Received: 2020-02-22 | Accepted: | Published: 2020$02-29$ 